\title{
Anthropometrically Determined Nutritional Status of Preschool Children in Anambra State, Nigeria
}

\author{
${ }^{* 1}$ Ilo Clementine. I., ${ }^{1}$ Agbapuonwu Noreen. E. ${ }^{2}$ Ogbonnaya, Ngozi. ${ }^{3}$ Obasi \\ Stella C., ${ }^{4}$ Makata Ngozi. E. ${ }^{2}$ Chinweuba Anthonia. U. $\&^{2}$ Iheanacho Peace.
}

\author{
${ }^{l}$ Department of Nursing Science. Nnamdi Azikiwe University Nnewi Campus Anambra State \\ ${ }^{2}$ Department of Nursing Sciences, University of Nigeria Enugu Campus Enugu State \\ ${ }^{3}$ Department of Human Kinetics and Health Education, Anambra State University Uli. \\ ${ }^{4}$ Department of Nursing Services, Enugu State Ministry of Health Enugu
}

\begin{abstract}
This study was designed to determine the nutritional status and growth of preschool children in Anambra State using vertical anthropometric measurements. Four objectives and one hypothesis were formulated in order to determine the mean measurements of weight, height, left mid upper arm circumference and head circumference of preschool children aged 3 - 5 years plus in the urban and rural communities of Anambra State. A cross sectional survey research design was used for the study to collect sampled data of 1280 preschool children in Anambra state. These data were organized and tested with inferential statistics of t-Test. The weights and heights were compared with the WHO/NCHS standards using graphs. The results showed that children aged 3-5 years plus in the urban areas indicated higher weight and height than those in the rural areas. These preschool children aged 3 - 5 years plus in both urban and rural locations had weights and heights that are higher than that of WHO/NCHS standards for their age. Based on the findings of the study, the researchers recommended that prevention of malnutrition should be given high priority in the implementation of the ongoing Primary Health Care programmes with particular attention paid to the rural population.
\end{abstract}

\section{Background to the Study}

\section{Introduction}

The nutritional status of an individual is that state or condition of health in relation to the consumption and utilization of nutrients in the body. The nutritional status of the child population according to Touwslager, Gielen and Derom (2011) is an important indicator of health and quality of life, reflecting not only the reality of this particular group, but also the society in which they live. Nutrition assessment in the community is essential for accurate planning and implementation of intervention programmes to reduce morbidity and mortality associated with malnutrition (Oninla, Owa, Onayade \& Taiwo, 2007). In this study nutritional status means the evident state of nutrition of an individual which is assessed by the measurement of the individual's body weight and height for age with respect to consumption of nutrients.

Normal growth according to Touwslager, et al. (2011) is the progression of changes in height, weight and head circumference that are compatible with established standard for a given population. Anthropometric measurement has been defined by Tanner (2001) as the systematic collection and correlation of measurements of certain parameters of the human body in order to assess nutritional status of the individuals and population groups, and as eligibility criteria for nutrition support programmes. Common anthropometric measures are height, weight, and mid-upper arm circumference (MUAC). Anthropometric measurement in form of growth monitoring is an essential component of child health supervision. Graphically, plotting anthropometric values for an individual indicates where the individual ranks in relation to all other individuals of the same age and gender.

The reference standards most commonly used to standardize measurements were developed by the US National Center for Health Statistics (NCHS) and are recommended for international use by the World Health Organization (WHO). Available evidence suggests that children from well-nourished and healthy families throughout the world grow at approximately the same rate and attains the same height and weight as children from industrialized countries (Garza \& de Onis, 2004; Pearce, 2002). The international reference standards can therefore be used for standardizing anthropometric data from around the world.

Studies on growth rate and nutritional status according to Onimawo and Cole (2010) have been well documented in developed countries as opposed to developing countries where not much works have documented anthropometric evaluations. This study is important in order to evaluate the nutritional status and establish growth standards (compared with WHO/NCHS standards) for weight and height of preschool children in Anambra state and to provide a baseline data for future research. 


\section{Purpose of the Study}

The study was aimed at determining the nutritional status and growth of preschool children in Anambra State using vertical anthropometric measurements with the objective of comparing them with the WHO/NCHS recommended standards for their age. Specifically the study at:

1. Determining the nutritional status of preschool children aged 3-5 years plus based on their weight for age Z-score.

2. Determining the nutritional status of preschool children aged 3-5 years plus based on their height for age Z-score.

3. Determining the mean measurements of weight, height, left mid upper arm circumference and head circumference of preschool children aged $3-5$ years plus in the urban and rural communities of Anambra State.

4. Comparing the measurements of the mean weight and height of preschool children aged $3-5$ years plus in rural and urban communities in Anambra State with those of WHO/NCHS recommended standards for their ages.

\section{Research Questions}

The following research questions guided the study:

1. What is the nutritional status of preschool children aged 3-5 years plus based on their weight for age Zscore?

2. What is the nutritional status of preschool children aged 3-5 years plus based on their height for age Zscore?

3. What are the mean measurements of the weight, height, left mid upper arm circumference and head circumference of preschool children aged $3-5$ years plus, in urban and rural communities of Anambra State?

4. How does the mean weight and height measurements of preschool children aged $3-5$ years plus, in urban and rural communities in Anambra State compare with those of WHO/NCHS recommended standard for their age?

\section{Research Hypothesis}

There is no statistically significant difference in the mean measurements of weight, height, left mid upper arm circumference and head circumference of preschool children aged $3-5$ years plus, in urban and rural communities in Anambra State.

\section{Method and Materials}

The research design adopted for this study, which is concerned with determining the nutritional status and growth of preschool children using vertical anthropometric measurements was the cross - sectional comparative survey design. This study basically focused on the assessment of the nutritional status and growth of children 3 - 5 years in Anambra state with respect to their weights, heights, left mid upper arm circumference and head circumference. The variables were delimited to their age and location of schools attended by the children. The study involved only public schools approved by the State Ministry of Education located in the six education Zones in Anambra State. The age limits were found in the early childhood/pre-primary education classes 3 - 5 years plus, according to the National Policy on Education (2004).

The target population of the study comprises all school children in the public nursery schools in Anambra state. Multi staged sampling technique was used to select the sample size of 1280 preschool children used for the study from one educational zones in the state. The anthropometric measurements of the height, weight and mid upper arm circumference of the preschool children were taken.

Data were collected using standard instruments for anthropometric assessment. The validity of the measurement tools was confirmed by experts. There was no test of reliability for the instruments for the study based on the fact that the instruments are standardized and valid instruments that have been recommended for such data collection. Height and weight were measured according to International Society for Advancement of Kinanthropometry (ISIAK) (2001) standards for anthropometric assessments. The children were on their school sport shorts and vest, and barefooted. They stood erect on the weighing scale, looked straight ahead and relaxed. The researchers took the readings when the pointer stabilized. Data were summarized using descriptive statistic of mean and standard deviation. Comparative analyses between variables were done using independent sample t-test. Statistical significance was set at $\mathrm{P}<0.05$ level of significance. All statistics were done using Statistical Package for Social Sciences (SPSS) for Windows (version 16.0). The data were presented in tables, bar charts and also plotted in line graphs for ease of comparism with those of WHO/NCHS recommended standards for their age. 


\section{Research Question 1}

\section{Results and Observations}

What is the nutritional status of preschool children aged 3-5 years plus based on their weight for age Z-score?

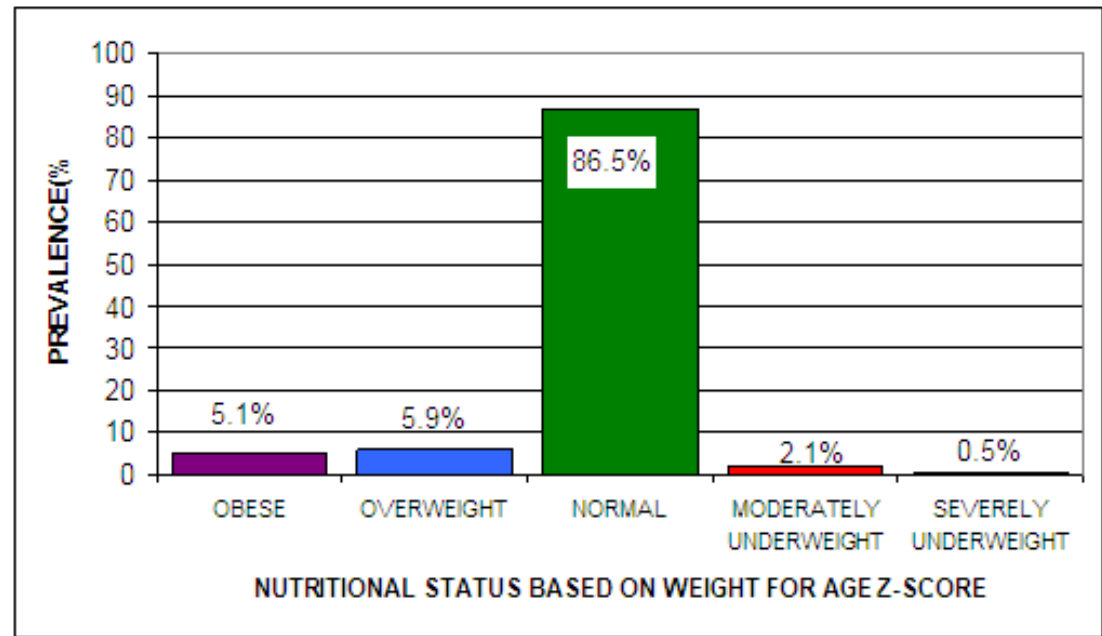

Fig.1. The Nutritional Status of Preschool Children Aged 3-5 Years plus Based on their Weight for Age Z-score

Data in figure 1 indicates that normal nutritional status was higher $(86.5 \%)$ than other status in all the anthropometric indicators studied. Overweight recorded 5.9\%; obese category was $5.1 \%$ while moderately underweight recorded $2.1 \%$. Children who indicated the least status were those with severe underweight $(0.5 \%)$.

\section{Research Question 2}

What is the nutritional status of preschool children aged 3-5 years plus based on their height for age Z-score?

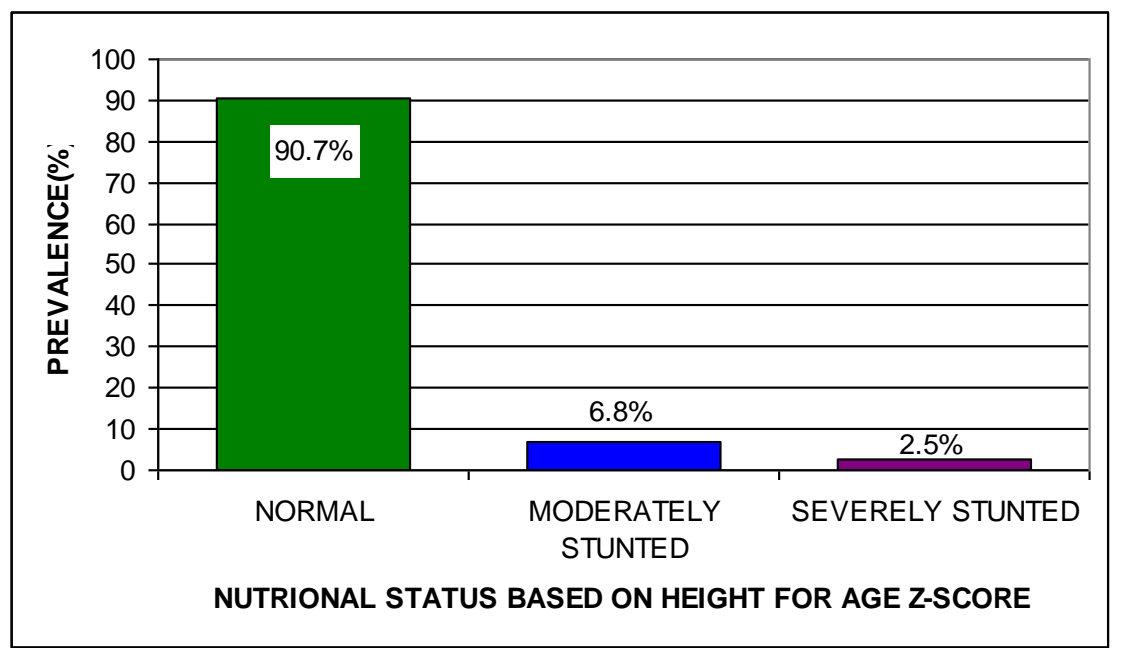

Fig. 2. The Nutritional Status of Preschool Children Aged 3-5 Years plus Based on their Height for Age

$$
\text { Z-score }
$$

Data in figure 2 indicates that normal nutritional status was higher (90.7\%) than other status in all the anthropometric indicators studied. Children who indicated the least status were those that were severely stunted $(2.5 \%)$ while those that were moderately stunted recorded $(6.8 \%)$.

\section{Research Question 3}

What are the mean measurements of the weight, height, left mid upper arm circumference and head circumference of preschool children aged $3-5$ years plus, in urban and rural communities of Anambra State? 
Table 1. Mean Weight, Height, Left Mid Upper Arm and Head Circumferences of Preschool Children Aged 3-5 Years plus According to Location.

\begin{tabular}{llcc} 
VARIABLES & $\begin{array}{c}\text { URBAN(n= 582) } \\
\text { X Measurement }\end{array}$ & $\begin{array}{c}\text { RURAL (n= 698) } \\
\text { x Measurement }\end{array}$ & $\begin{array}{c}\text { x Difference } \\
-\end{array}$ \\
& & & \\
\hline & & & \\
Weight $(\mathrm{Kg})$ & 17.08 & 16.72 & 0.36 \\
Height $(\mathrm{Cm})$ & 1.04 & 1.03 & 0.01 \\
MUAC $(\mathrm{Cm})$ & 16.31 & 16.35 & 0.04 \\
Head Circumference $(\mathrm{Cm})$ & 50.25 & 50.14 & 0.11 \\
\hline
\end{tabular}

Table 1 shows that the urban preschool children of Anambra State aged 3-5 years plus had better mean weight $(17.08 \mathrm{~kg})$, mean height $(1.04 \mathrm{~m})$ and mean head circumference $(50.25 \mathrm{~cm})$ than their rural counterparts who had $16.72 \mathrm{~kg}, 1.03 \mathrm{~m}$ and $50.14 \mathrm{~cm}$ as their mean weight, mean height and mean head circumference respectively. The table also shows that the rural preschool children of the study had $16.35 \mathrm{~cm}$ mean upper arm circumference while their urban counterparts had $16.31 \mathrm{~cm}$.

\section{Research Question 4}

How does the mean weight and height measurements of preschool children aged $3-5$ years plus, in urban and rural communities in Anambra State compare with those of WHO/NCHS recommended standards for their age?

Table 2: Mean Weight of Preschool Children Aged 3-5 Years plus Compared With Those of WHO/NCHS Reference Values in Both Urban and Rural Areas.

\begin{tabular}{cccc}
\hline AGE (YEARS) & $\begin{array}{c}\text { MEAN WEIGHT OF } \\
\text { CHILDREN IN URBAN } \\
\text { LOCATIONS(Kg) }\end{array}$ & $\begin{array}{c}\text { MEAN WEIGHT OF } \\
\text { CHILDREN IN RURAL } \\
\text { LOCATIONS(Kg) }\end{array}$ & $\begin{array}{c}\text { WHO/NCHS } \\
\text { REFERENCE } \\
\text { MEAN } \\
\text { WEIGHT(Kg) }\end{array}$ \\
\hline & 15.3 & & \\
3 & 17.4 & 15.4 & 14.3 \\
5 & 18.1 & 16.8 & 16.3 \\
& 17.7 & 17.9 \\
\hline
\end{tabular}

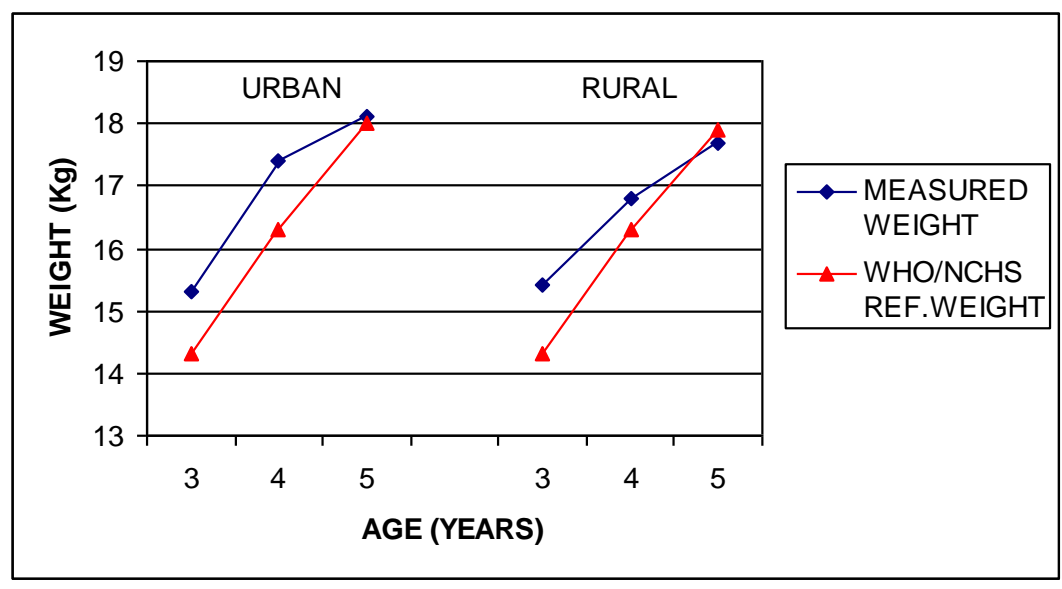

Fig. 3. The Mean Weight of Preschool Children Aged 3-5 Years plus Compared with those of WHO/NCHS Reference Values in both Urban and Rural Areas.

Table 2 and Figure 3 show that the urban and rural preschool children of the study aged 3 - 4 years weighed more than the WHO/NCHS reference weight for their age. The table also shows that among the preschool children of the study aged 5 years plus, the mean weight of preschool children in urban locations and that of WHO/NCHS reference standard were better than those in rural locations, but these children in urban locations weighed more than the WHO/NCHS reference standard. 
Table 3 Mean Height of Preschool Children Aged 3-5 Years plus Compared With Those of WHO/NCHS Reference Values in Both Urban and Rural Areas.

\begin{tabular}{cccc} 
AGE(YEAR) & $\begin{array}{c}\text { MEAN HEIGHT OF } \\
\text { CHILDREN IN } \\
\text { URBAN LOCATIONS }\end{array}$ & $\begin{array}{c}\text { MEAN HEIGHT OF } \\
\text { CHILDREN IN RURAL } \\
\text { LOCATIONS }\end{array}$ & $\begin{array}{c}\text { WHO/NCHS } \\
\text { REFERENCE }\end{array}$ \\
\hline 3 & 98.2 & 98.3 & 95.1 \\
4 & 104.5 & 105.3 & 102.9 \\
5 & 109.6 & 105.5 & 109.2 \\
\hline
\end{tabular}

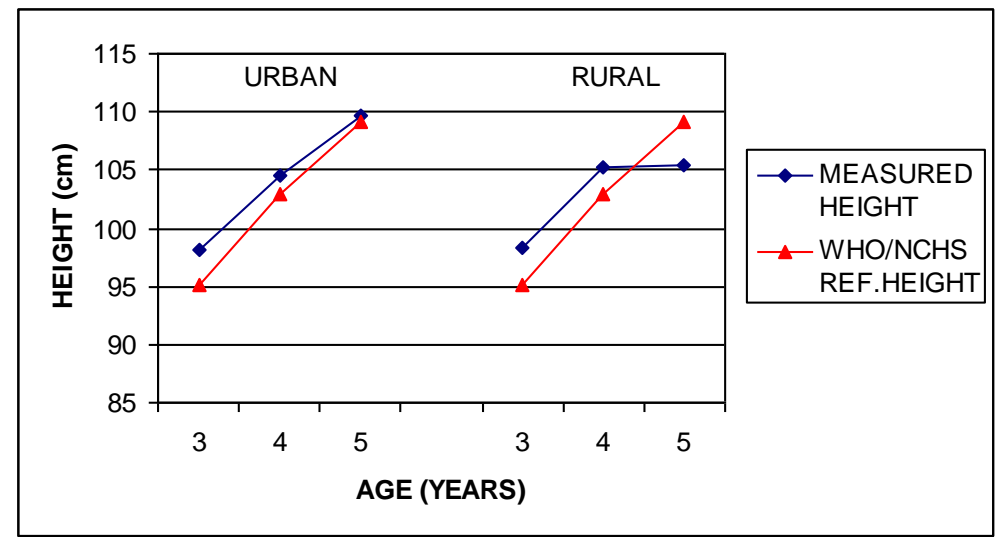

Fig. 4. The Mean Height of Preschool Children Aged 3-5 Years plus Compared with those of WHO/NCHS Reference Values in both Urban and Rural Areas.

Table 3 and Figure 4 show that the mean height of the preschool children in urban and rural locations aged 3 - 4 years were greater than that of WHO/NCHS reference standard for their age. The table also show that among the preschool children of the study aged 5 years plus, the mean height of preschool children in urban locations and that of WHO/NCHS reference standard were better than those in rural locations, but these children in urban locations had better mean height $(109.6 \mathrm{~cm})$ than the children of WHO/NCHS reference values who had a mean height of $109.2 \mathrm{~cm}$.

\section{Research Hypothesis}

There is no statistically significant difference in the mean measurements of weight, height, left mid upper arm circumference and head circumference of preschool children aged $3-5$ years plus, in urban and rural communities in Anambra State. The data verifying this hypothesis are contained in Table 4.

Table 4. Summary of the t-test Comparism of the Mean Weight, Height, MUAC and Head Circumference of Nursery School Children in Anambra State Aged 3-5 Years plus According to Location

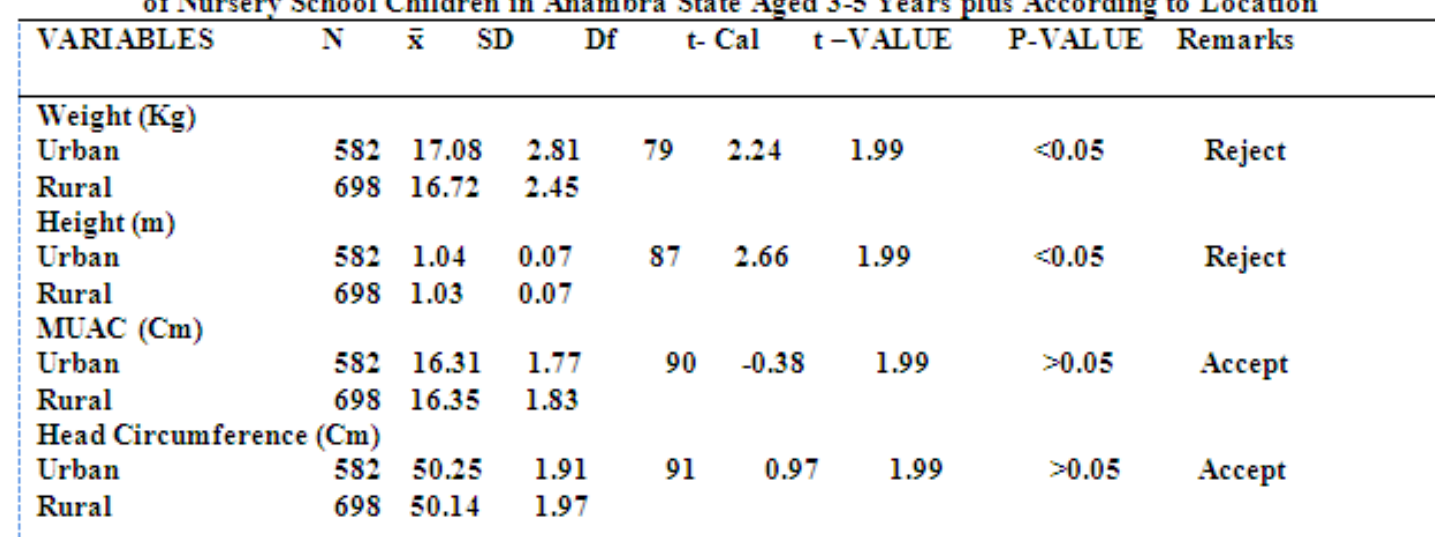

Table 4 presents the t- test summary of the mean weight, height, MUAC and head circumference of the preschool children in urban and rural locations of Anambra State aged 3-5 years plus. The table shows that there were significant differences between the urban and rural preschool children in terms of their mean measurement weights and heights. The table also shows that there were no significant differences between the urban and rural children of the study in terms of their mean measurements of MUAC and head circumference. 


\section{Discussion of Findings}

The facts emerging from this study are discussed under the following subheadings:

Results related to Nutritional Status.

Results related to weights, mid upper arm and head circumference.

Results related to heights.

\section{Results Related to Nutritional Status:}

The nutritional status of preschool children were assessed using different anthropometric indicators. The results show that the mean indicators of nutritional status for preschool children aged $3-5$ years plus in Anambra state were found within the normal range of $86.5 \%$ to $99 \%$ (Figures $1 \& 2$ ). This was expected because there has been a lot of community awareness programmes particularly at the household level on behaviours that will promote the nutritional wellbeing in the communities. The observation of high prevalence of normal nutritional status could be attributed to various nutrition policy and programmes put in place by the government and nongovernmental organizations for child survival in the last decade.

The normal nutritional status of the children in this study is in contrast to the findings of studies carried out in other parts of Nigeria (Ogechi, Onimawo \& Ukegbu, 2007; Nwokolo, Ifada, Onochie \& Olomu, 2007 and Cole, Timori, Odumbako \& Aminu, 2002) who found out that children had nutritional status below normal.

The overall prevalence of malnutrition in form of moderate underweight $(2.1 \%)$, moderate stunting $(6.8 \%)$, moderate wasting $(4.8 \%)$ and severely stunting $(2.5 \%)$ were observed in children $3-5$ years using weight-forage and height-for-age z-scores respectively. The study showed that malnutrition (underweight, wasting and stunting) was a major public health problem among preschool children in Nigeria, particularly in the rural areas. This corroborates the findings of other studies which reported strong association between malnutrition and socio-economic status and cultural factors (Nwokolo, et al. 2007; Onimawo and Ukegbu 2005; Osisanya, Awala \& Cole, 2002; Onimawo \& Cole, 2000).

\section{Results Related to Weights, Mid Upper Arm and Head Circumference:}

Findings of this study revealed that the mean scores of the weight, mid upper arm and head circumferences of preschool children aged $3-5$ years plus in Anambra state were within normal range. However when compared between urban and rural locations, children in the urban areas indicated higher mean weight $(17.8 \mathrm{~kg})$ and mean head circumference $(50.25 \mathrm{~cm})$ than those of their rural counterpart. This might be due to differences in the socio-economic status of their parents because most of the children attending schools in rural areas are from relatively low socio-economic background. Therefore the low socio-economic backgrounds of these children suggest that factors such as education, occupation and economic status of their parents may account for the differences. In addition, the usual higher prevalence rates of intestinal parasites in the rural community compared with the urban could contribute to the disparity in the growth rate of these children

The higher mean weight and mean head circumference of preschool children in urban communities in the present study is in agreement with those of other studies among preschool children in Nigeria (Ogechi. et al., 2007; Nnanyelugo, Ngwu \& Okeke, 2008) and other countries. In Nigeria there are more children from high socio-economic classes in the urban than in the rural communities. This probably accounted for the better growth rate of the school children in the urban than rural locations.

The weight of preschool children aged $3-5$ years plus in both urban and rural locations were greater than that of $\mathrm{WHO} / \mathrm{NCHS}$ reference weight $(\mathrm{P}<0.001)$. The graphs obtained from this study compared favourably with the WHO standards and showed that it did not fall below the recommended standards. This is in contrast to the study by Amuta and Houmsou (2006), where they found out that the mean weight of the children at all ages were much lower compared to WHO/NCHS reference standard.

\section{Results Related to Heights.}

The height of preschool children aged $3-5$ years plus in both urban and rural locations were higher than that of WHO/NCHS recommended reference height for their ages. Findings by Habicht, Martorell and Melina (2004) and Pearce, (2002) have shown that factors such as socio-economic class and genetic factors have influence on the weight and height of children. In this connection, Burren (2009) reported that growth and development retardation are common in city slums and rural areas where there is poverty.

\section{Implications of the Study}

The findings of the study indicated that location has significant influence on the anthropometric indicators of the preschool children. What this implies is that children in the urban locations have adequate dietary intake than their rural counterparts. This therefore calls for health education of the parents and care givers on the need for adequate nutrition and elimination of some of the factors that contribute to low dietary intake especially in the rural areas. This is essential in order to identify and reduce the risk of inadequate 
nutrition, improve nutrition, educate caregivers and to refer conditions manifested by growth disorders for adequate management. Parents should monitor the type and quantity of food their children consume and make sure they are adequate in quantity and quality. It is recommended that prevention of malnutrition should be given high priority in the implementation of the ongoing Primary Health Care programmes with particular attention paid to the rural population.

\section{Conclusion}

Growth monitoring has been identified as an opportunity for health care providers to increase awareness and provide anticipatory guidance on the importance of healthy feeding and eating practices. Growth monitoring is essential in order to identify and reduce the risk of inadequate nutrition, improve nutrition, educate caregivers and to refer conditions manifested by growth disorders for adequate management. There is therefore the need for regular measurements of the weight, height and mid upper arm and head circumference of Nigerian children through the school health services in order to monitor their growth and nutritional status. The need to educate mothers and caregivers to bring their children for growth monitoring and the importance of referring conditions manifested by growth disorders to health care providers for adequate management can never be over emphasized.

\section{References}

[1]. Amuta, A. C., \& Houmsou, M. M. (2006). Assessment of the nutritional status of school children aged 6-17 years in Makurdi Benue State. Nigeria. Pakistan Journal of Nutrition $6(6), 83-92$.

[2]. Burren, C.P. (2009). Normal and Abnormal Growth. United Bristol care NHS Trust. London: Cambridge University Press.

[3]. Cole, A. H., Timori, O.F., Odumbako, S.O., \& Aminu, K. S. (2002) Nutrient intakes, Basal Metabolic Rate (BMR) and body congestion of Nigerian female adolescents. Nigerian Journal of Nutrition Science, 36, 97-104.

[4]. Garza C. \& de Onis M., For the WHO Multicenter Growth Reference study Group (2004). Rationale for developing a new international growth reference. Food and Nutrition Bulletin, 25 (Suppl.), S 10 - S14.

[5]. Habicht, J. P., Martorell, H. A., \& Melina; V. W. (2002). Standardization procedure for the collections of weight and height data in the field. Pan American official Bulletin of Health. 76, 375-384.

[6]. International Society for the Advancement in Kinanthropometry (ISIAK) (2001). International Standard for Anthropometric Assessment. Unerdale, SA, Australia: ISIAK 1-133

[7]. National Policy on Education. (NPE). (2004). National Policy on Education. (Rev. ed.). Abuja Nigeria: NERDC Press.

[8]. Nnanyelugo, D.O., Ngwu, E. K, \& Okeke, E. K. (2008). Determination of energy expenditure in humid tropical climate and its relationship to dietary intake. Nigerian Journal of Nutrition Science, 20 \& 21, 21-28.

[9]. Nwokolo, S., Ifada, K., Onochie, O. \& Olomu, J. (2007). Anthropometric Assessment of Nutritional status and Growth of 10-20 year old individuals in Benin City metropolis (Nigeria). Pakistan Journal of Nutrition 5(2), 117-121.

[10]. Ogechi, U. P., Onimawo, I. A., \& Ukegbu, A. U (2007). Nutritional study and energy intake of Adolescent in Umuahia urban, Nigeria. Pakistan Journal of Nutrition 6 (6), 641-646.

[11]. Onimawo, I A., \& Cole, A.H. (2010). A Longitudinal study of changes in body composition of young adult in Nigerians. Nigerian Journal of Sociology. 36, 47-57.

[12]. Onimawo, I. A., \& Ukegbu, P. O. (2005). Energy intake and Energy expenditure of institutionalized female adolescents in a Nigerian secondary school. Journal of Sustainable Agriculture and Environment, 9, 34-32.

[13]. Oninla, S. O., Owa, J. A., Onayade, A. A., \& Taiwo, O. (2007). Comparative Study of Nutritional Status of Urban and Rural Nigerian School Children. Journal of Tropical Paediatrics. 53 (1), 39-43

[14]. Osisanya, J. O., Awala, M. A., \& Cole, A. H. (2002 Dec.) Anthropometry and body composition of adolescent boys in a Federal Government Institution (A case study of Kings College Lagos.) Proceedings of the 33rd Annual conference of the nutritional society of Nigeria, 23:96-101.

[15]. Pearce, E.O. (2002). A General textbook of Nursing. London: Faber \& Faber

[16]. Tanner, J.M. (2001). Education and Physical growth. Implications of the study of children's growth for education theory and practice. London: University Press.

[17]. Touwslager, R.N., Gielen, M. \& Derom, C. (2011) Determinants of infant growth in four age windows: a twin study. Journal of Paediatrics 56, 158:566 